\title{
THE AUDITORY SENSE OF THE HONEY-BEE
}

\author{
N. E. MCINDOO \\ Bureau of Entomology, Washington, D. C. \\ TWENTY-SIX FIGURES \\ CONTENTS
}

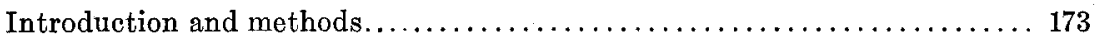

So-called vocal organs of insects.................................. 175

1. Sound-producing organ of honey-bee......................... 175

a. Experiments to determine how bees make sounds............. 175

b. Morphology of sound-producing organ $\ldots \ldots \ldots \ldots \ldots \ldots \ldots \ldots \ldots \ldots$

2. Sound-producing organs of other insects................... 179

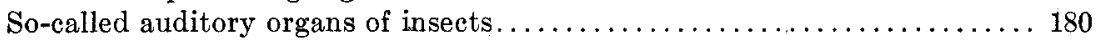

Supposed auditory organs of honey-bee..................... 180

$a$. Structure of Johnston's organ . . . . . . . . . . . . . . . . . . . 180

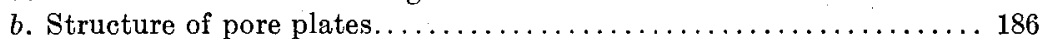

c. Structure of other antennal organs ....................... 189

d. Structure of tibial chordotonal organs.................... 190

e. Structure of tibial ganglion cells....................... 195

Summary ............................................. 196

Literature cited........................................ 198

\section{INTRODUCTION AND METHODS}

Much has been written about the auditory sense of insects, but critics still contend that it has never been demonstrated beyond a doubt that any insect can really hear. Most students on insect behavior believe that insects can hear, but only Turner and Schwarz ('14) and Turner ('14) seem to have produced good experimental evidence; however, they used only moths in their work. Much less is known about the sound perceptors in insects, and still it is not generally known how insects make sounds which are supposed to be heard by them.

It is usually believed that insects can hear for the three following reasons: 1) many have special sound-producing organs; 2) some have so-called auditory organs, and, 3) many of the experimental results obtained indicate that insects can hear. 
In regard to the buzzing of insects, there are four old views to explain how the noise is made, as follows: 1 ) by the rapid vibration of the wings; 2 ) by the vibration of the thorax; 3 ) by a special modification of the occlusor apparatus in the stigmata, and, 4) in Diptera, by the vibration of the halteres. Relative to Diptera and Hymenoptera, Pemberton ('11) and Aubin ('14) show that none of the above views hold good. They determined that the buzzing is made by the extreme bases of the wings, as is shown for the honey-bee in the present paper. The humming, or more common noise produced by the wings, is made by the distal portions of the wings.

We should not expect insects to respond to sounds which have no significance to them, nor to sounds not in their category, because they may not hear the sounds that we do. The number of vibrations perceptible to the average human ear varies from 32 to 60,000 per second. Now it may be that the insect ear is so poorly developed that it can hear only sounds having vibrations below 32 per second. It may also be that the sense of hearing in insects is on no higher plane than that advocated by Forel ('08), who believes that insects do not hear, at least as we do, but compares this perception in them to that in deaf-mutes who feel the rolling of a carriage at a distance.

Bee-keepers are agreed that bees can hear, yet they cannot prove it. Von Buttel-Reepen ('07), a scientist and an experienced bee-keeper, in discussing the behavior of bees has much to say about their auditory perception, but still he produces no experimental evidence to support his strong statements.

To obtain material for the structure of the sound-producing organ, adult bees were used; but for a study of the so-called auditory organs, young bees, nineteen and twenty-one days old (counting from the time the eggs were laid) were employed. Fresh material was fixed in the modified Carnoy's fluid and was embeded in $60^{\circ}$ paraffin. Sections were cut 5 and $8 \mu$ in thickness, and were usually stained in Ehrlich's hematoxylin and eosin, but a few of them in eosin alone. All the drawings are original and were made by the writer at the base of the microscope usually with the aid of a camera lucida. 


\section{SO-CALLED VOCAL ORGANS OF INSECTS}

In the higher animals the vocal organs are located in the throat, but in insects we should not expect to find their vocal organs in the buccal cavity, because this class of animals has a totally different organization. Hence, we must look elsewhere for the vocal organs of insects.

\section{Sound-producing organ of honey-bee}

In 1911, while determining that bees have an olfactory sense, the writer also ascertained that they have a means of making a piping or squealing noise.

a. Experiments to determine how bees make sounds. Hundreds of worker bees with wings pulled off or cut off were tested, and from mere observations it appeared that the squealing noise was made by the thorax. To be sure that the noise was made by the thorax, the abdomens of several bees were cut off. These mutilated bees could walk fairly well and when irritated made the squealing noise." Several other bees with both heads and abdomens cut off were likewise tested; these were so badly mutilated that in only one case did a thorax make the noise. Bees with wings cut off, when observed under a binocular, further confirmed the view that the squealing noise is made solely by the thorax, because the bases of the wings were seen to vibrate rapidly.

In 1920 the preceding line of experimentation was continued, and the following results were obtained. The loud buzzing of bees is made by the distal portions of both pairs of wings, while the squealing noise is made only by the bases of the front wings. When worker bees or drones were squeezed, or when their wings were held firmly, or were cut off or pulled off, these insects usually made the squealing noise. When no noise was heard, the insect being tested was placed on a large inverted pan lying on a table. The pan thus serving as a resonator usually intensified the feeble noise so that the human ear could hear it. Bees with the wing stubs glued did not make the noise, but after dissolving off the glue the insects made the noise as usual. When the muscles attached to the roots or axillaries of the wings were cut, the 
squealing noise ceased for all time, and when the thorax of a live bee was held gently between the fingers the tingling sensation perceived indicated that these muscles vibrate very rapidly, setting in motion the axillaries and membranes in the bases of the wings. A microscopical examination of all the front wings pulled off showed that every bee with wings thus detached was able to squeal so long as one or two intact axillaries remained in the thorax.

Besides the buzzing and squealing noises made by bees, the writer often heard a crackling sound while observing these insects flying around an alighting-board. He could not detect how this sound is made, but imagined it produced by the wings striking together accidentally.

All attempts, except one, trying to get bees to respond to the squealing of other bees failed. Or at least the bees exhibited no reactions which could be attributed as signs of hearing. Nevertheless, one squealing bee was held in a hidden position a few inches from an alighting-board; at once one of the many workers on this board seemed to take notice and flew to the screen behind which the squealing bee was hidden, and then it came immediately to the squealing bee, which it began to examine by running around it and smoothing its hair.

A queen bee, resting on a comb with workers surrounding her, when squeezed, squealed and the near-by workers became excited. Such experiments really do not mean much, because too many interfering factors cannot be eliminated. The original plan of the writer was to carry on experiments in which he hoped to be able to classify and to record on phonograph records the various sounds heard in a hive of bees. If this were possible, he intended to reproduce these sounds and then to determine whether or not bees respond to them. When he was transferred from the division of Bee Culture, this line of experimentation was discontinued.

b. Morphology of sound-producing organ. Several live worker bees and drones were held under a binocular and the following observations were recorded: When a bee is held by the legs it buzzes continuously. The wings are held straight out at right 
angles; their anterior margins move little, but their flexible posterior portions vibrate rapidly; their bases do not vibrate, but move slowly in and out and backward and forward; no squealing was heard, but the muscles in the thorax vibrate more or less slowly. When one-half of each wing was cut off, a faint buzzing and a feeble squealing noise were heard. When the front wings were cut off as closely as possible and the hind wings were pulled out by the roots, no buzzing was heard, but the squealing noise was quite pronounced. While the bases of the front wings

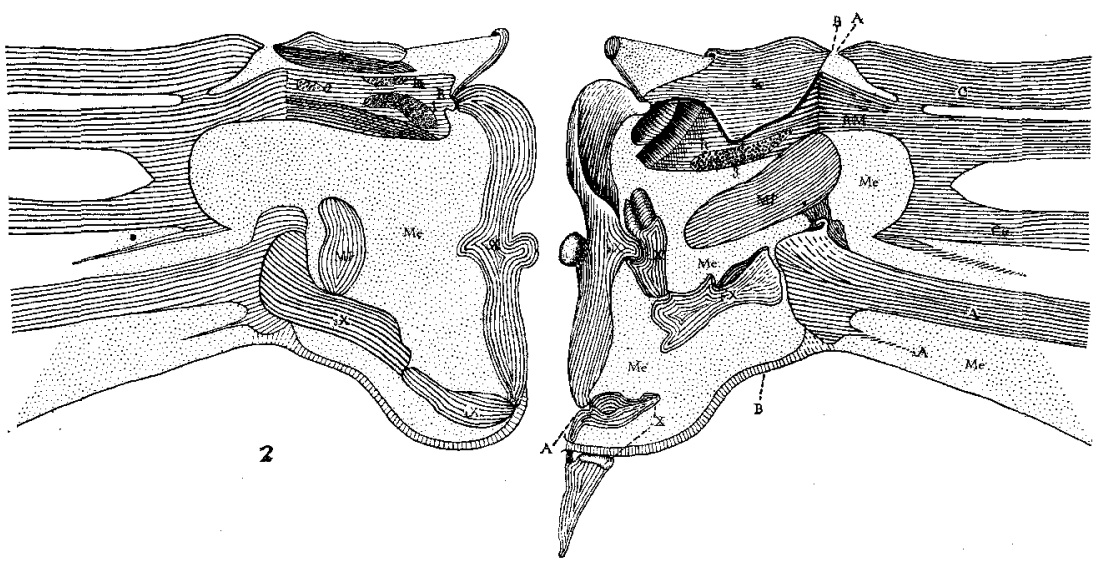

Figs. 1 and 2 Base of right front wing of a worker honey-bee, showing special sound-producing apparatus, consisting of membranes $(M e)$ lying between axillaries $(1,2,3$, and $4 X)$, median plate $(M P)$, head of radius $(R)$, subcosta $(S c)$, costa $(C)$, union of radius and media $(R M)$, cubitus $(C u)$, and anal veins ( 1 and $3 A$ ). Nos. $1,1 a, 2$, and 3 , groups of olfactory pores. Fig. 1 , dorsal view, and fig. 2 , ventral view. $\times 40$.

vibrated, two weak lines in them were exhibited, as indicated by lines $A A$ and $B B$ in figure 1 . The first one, starting between the ends of the costa $(C)$ and subcosta $(S c)$ and ending between the first $(1 X)$ and fourth axillaries $(4 X)$, resembles a stiff hinge; while the second one, starting from the same source, passes through the weak point in the union of the radius and media $(R M)$ and ends between the first anal $(1 A)$ and third axillary $(3 X)$. This line, along which the wing usually breaks when this appendage is carelessly pulled off, is more rigid than the other one. 
While observing a squealing bee, the saddle-shaped subcosta (fig. 1, $S c$ ) rotated quickly on the head of the radius $(R)$ which also vibrated; the bases of the cubitus $(C u)$, first and third anal veins $(1 A$ and $3 A$ ), and the membranes $(M e)$ between them likewise vibrated, and the median plate $(M P)$ and tegula were observed to move slightly. When the tegula which covers the axillaries was pulled off, the first, second, and third axillaries $(1 X, 2 X$, and $3 X)$ and the membranes $(M e)$ between them were seen to vibrate.

It was not possible to observe the ventral surface (fig. 2) of the base of the wing on the living bee, but a study of its anatomy shows that this surface is better adapted to produce sounds than is the dorsal surface (fig. 1). Reference to figure 2 shows that there is twice as much membrane capable of being vibrated on this surface as on the other surface, due to the fact that the subcosta ( $S c)$, head of the radius $(R)$, and median plate $(M P)$ are considerably smaller than they are on the other side. In fact, all the membranes, represented by dots in figure 1, were observed to vibrate, and all of those in figure 2, likewise represented, also probably vibrate. Thus it is evident that the extreme bases on these wings make a good sound-producing organ.

Figure 1 is partly copied from Snodgrass ('10), but the present writer carefully verified all the sclerites here represented, and then made a careful study of the ventral surface (fig. 2), which the former writer did not illustrate. Relative to the muscles, attached to the axillaries, and to the mechanism producing the wing motion, the reader is referred to Snodgrass' bulletin, page 65 .

In this study the group of olfactory pores on the front wings have been more carefully observed than they were formerly by the writer ('14 a). Instead of three groups, there are four groups of them; the fourth group, now numbered $1 a$ in figure 2, was formerly overlooked in superficial observations, but was called no. 2 in figures 19 and 20 , page 328 . Groups 1, 1a, and 2 are really located on the head of the radius (fig. 2, $R$ ), and not on the subcosta, and group 3 lies on the other side of the same sclerite (fig. 1), and not on the median plate. 


\section{Sound-producing organs of other insects}

Pemberton ('11) experimented with several species of Syrphidae, house-fly, honey-bee, and bumble-bee. He says that they do not produce audible sounds by the spiracles or tracheae, but that all humming or buzzing sounds made by them are produced solely by the wings, either by their vibration in the air or by the wing bases striking against the body wall. This author did not study the anatomy of the wing bases.

Aubin ('14), as well as Pemberton, used the syrphid or common drone-fly (Eristalis tenax) in all his detailed experiments. The former author, after experimenting with this fly and after carefully identifying all the parts in the bases of its wings, concludes that the buzzing sound is made by a rapid vibration of certain thoracic muscles, attached to a particular sclerite, which strikes the thorax at a given point. The resonant apparatus, consisting of another sclerite and its attached membranes, is thrown into a state of vibration, producing the buzzing sound which is about an octave higher than the humming noise, made by the distal portions of the wings. In the honey-bee, according to the observations of the present writer, no part of the wing base strikes the thorax during the vibration. Aubin believes that, according to the laws of acoustics, the resonant areas in the wing base of this fly might respond to the buzzing of other flies and thus form one of the elements of an auditory apparatus. If this were true, a nervous connection would be necessary. In all probability, no such connection exists in this fly, and certainly not in the honey-bee.

Judging from the known sound-producing apparatus, and socalled auditory organs in crickets, grasshoppers, and katydids, the males are usually neither deaf nor dumb, but the females are always dumb, although not generally deaf. The males of crickets, katydids, and of some grasshoppers make sounds by rubbing their wings together, whereas other grasshoppers make sounds by rubbing the hind legs against the wings. Both sexes possess so-called ears, which in crickets and katydids (Locustidae) are found on the front tibiae, but in grasshoppers (Acrididae) on the abdomens. As far as known, the female cicada is both 
deaf and dumb, but her mate is only deaf, his sonorous soundproducing organ being found in the abdomen. "Happy is the cicada, since its wife has no voice," says Xenarchos, could just as well be said about the males of crickets, grasshoppers, and katydids. Graber, after cutting off the front tibiae of crickets and katydids, found that they responded as well to a violin and to their chirping and singing as before the operation.

Stridulation, special sound-producing apparatus, and various types of supposed auditory organs have been described in true bugs, moths and butterflies, flies and mosquitoes, beetles, and ants, and also in a few larvae and pupae, yet we know very little about this subject.

\section{SO-CALLED AUDITORY ORGANS OF INSECTS}

Since insects have special sound-producing organs, it is natural to suppose that they also have auditory organs. The so-called auditory organs of Orthoptera and of certain other insects, mentioned above, need not be further discussed here, because Comstock ('20, pp. 145-154) has recently given a good summary on this subject.

\section{Supposed auditory organs of honey-bee}

In the following pages the descriptions of five supposed sound receptors are given, and Janet ('11) mentions a sixth one in the bee. From his brief description and drawing the details of this one cannot be interpreted. The following is all that Janet says about it: The chordotonal nerve departs from the antennal nerve a short distance from the brain, and runs toward the integument where it is inserted at a point beneath and a short distance from the articular edge of the antenna. From this point of insertion departs one end of a fusiform chordotonal ganglion, whose other end gives rise to a terminal cord which runs toward the articular membrane of the antenna, and is there inserted. The present writer has not studied this organ, but from the above brief description he would eliminate it as a possible auditory organ.

a. Structure of Johnston's organ. Johnston ('55) pointed out a supposed auditory organ in the second antennal segment of the 
culex mosquito. This structure, later called Johnston's organ, was thoroughly investigated by Child ('94 a, b), who saw it in all the insect orders examined, except one. He found it in several genera of Diptera, one genus of Hymenoptera, and in one or more genera each of Coleoptera, Lepidoptera, Neuroptera, Pseudoneuroptera, and Hemiptera (Homoptera). Apparently he did not cxamine the honey-bee, but found it in a wasp (Vespa vulgaris) well developed, although the articular membrane to which the sense cells are attached is not complicated as he found it in mosquitoes and as the present writer saw it in the honey-bee. Of the many specimens examined, Child found this organ most highly developed in the male mosquito (Comstock, '20, pp. $152-154$, for a general description). He also saw sense organs in the second antennal segments of Orthoptera, but decided they were not Johnston's organs. Recently these have been described as olfactory pores by the present writer ('20).

The distal end of the second antennal segment (ng. 3, 2) is considerably larger than the proximal end, but the proximal end of the third segment $(3)$ is the narrowest portion of the antenna. When examining the extreme distal end of the second segment under a low-power lens, a circle of irregular structures $(J)$, somewhat resembling a miniature mountain chain in shape, passes completely around the segment. Observing a crushed segment under a high-power lens, it will be noted that these structures, known as chitinous knobs (fig. $4, K$ ) from now on, lie in the articular membrane between the second and third segments. The top line in figure 4 represents the union of this membrane with the second segment, and the bottom line the union of the same membrane with the third segment. As an average for each caste, a worker has 70 of these knobs; a queen, 72, and a drone, 100.

Oblique sections through the articular membrane show that it (figs. 5 and $6, A r t M$ ) is very thin, that the ends of the knobs $(K)$ fit into sockets $(S)$ in the chitin $(C h)$ of the third segment, and that soft, flexible strands of chitin (figs. 6 and 12, $(h)$ firmly bind the two segments together. In fact, the hard, rigid chitin (represented by solid black) of the articular membrane (figs. 7 and 12, ArtM) is reenforced by a layer of soft, flexible 


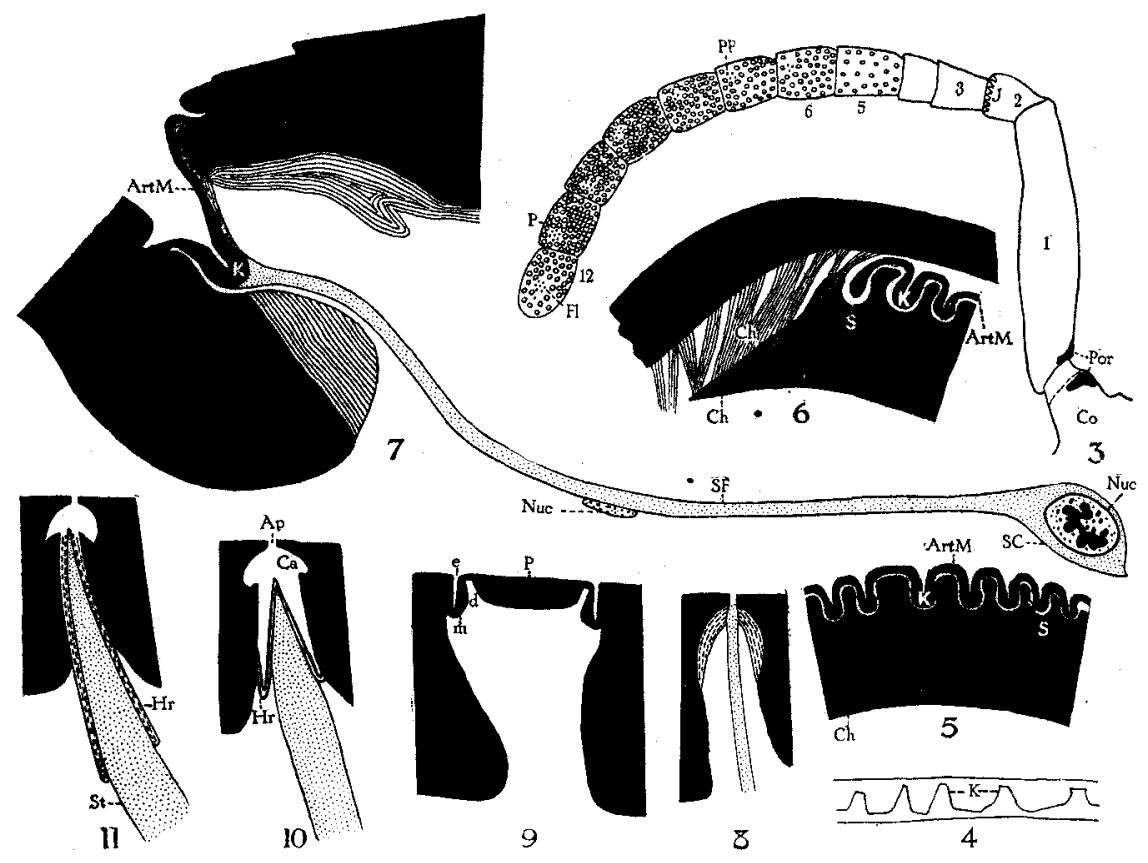

Figs. 3 to 11 Antennal sense organs of honey-bee. Fig. 3, dorsal surface of right antenna of worker, showing following: Two groups of olfactory pores $(P o r)$ on condyle ( $\mathrm{Co}$ ) and scape (1); flagellum, consisting of second to twelfth segments (2 to 12), bearing Johnston's organ $(J)$, pit pegs $(P P)$, pore plates $(P)$ and Forel flasks $(F l)$; the tactile hairs and pegs are not represented; $\times 20$. Fig. 4, superficial appearance of Johnston's organ on worker antenna, showing knobs $(K) ; \times 320$. Figs 5 and 6 , oblique sections through Johnston's organ in drone antenna, showing knobs $(K)$ of articular membrane (ArtM) in sockets $(S)$ of chitin $(\mathrm{Ch})$, and soft, flexible strands of chitin $(\mathrm{Ch})$ which firmly bind second and third segments together; $\times 500$. Fig. 7 , from three consecutive longitudinal sections of nineteen-day-old worker antenna, showing sensory part of Johnston's organ, consisting of sense cell $(S C)$, its nucleus $(N u c)$ and sense fiber $(S F)$ and probably the latter's nucleus $(N u c)$; note distal end of sense fiber attached to knob $(K)$ of articular membrane $(A r t M) ; \times 1000$. Figs. 8 to 11, internal structure of antennal organs; $\times 1000$. Fig. 8 , olfactory pore from worker condyle. Fig. 9, pore plate from drone antenna, showing plate $(P)$, two grooves $(d$ and $e$ ), and double hinge-like membrane $(m)$. Figs. 10 and 11, pit peg and Forel flask, respectively, from worker antenna, showing semitransparent hair $(H r)$, nerve strand $(S t)$, cavity $(C a)$, and aperture $(A p)$. 
chitin (represented by broken lines). Consequently, instead of this articulation being weak, it is as strong as any other, and when broken by a steady pull, the articular membrane remains fastened to the third segment, showing that the knobs, although having considerable play in their sockets, nevertheless lend considerable strength to the articulation.

Longitudinal sections through the second antennal segment show the following: A large group of sense cells (fig. 12, SC) lies on either side of the section; two large antennal nerves $(N)$, called internal and external olfactory nerves by Janet ('11), run through the center of the segment and at various places unite with the groups of sense cells, as shown in figure 12, and a large trachea $(T r)$ runs near the nerves and sends out branches here and there.

A thorough study of these sections under an oil-immersion lens shows the following: The elliptical sense cells (fig. 7, SC) have conspicuous nuclei $(N u c$ ), short nerve fibers (fig. 12, $N F$ ) which run into the nerves, and long and comparatively large sense fibers $(S F)$ which run in bunches toward the articular membrane. About half-way between the sense cell and articular membrane may be seen small slender nuclei (fig. $7, N u c$ ), some of which seem to lie on the surface of the sense fibers, but it is more likely that these are hypodermal nuclei, although the nuclei in the hypodermis (fig. 12, Hyp) usually are round and much larger. When the bunches of sense fibers reach the flexible strands of chitin $(C h)$ the individual fibers separate, run between these strands, then unite singly with the inner ends of the knobs $(K)$.

Figure 12 is a diagram showing most of the second segment in longitudinal section and in perspective, and a small portion of the third segment in both cross and longitudinal section and in perspective. It is noted that the thin articular membrane (ArtM), bearing the chitinous knobs $(K)$, is unprotected and fully exposed to the outside air. Two of the knobs are cut lengthwise, showing the cone-shaped cavity which opens to the exterior. The other knobs are heavily shaded, showing that they are buried in the articular membrane. 
A glance at figure 12 shows that the articular membrane resembles the head of a drum and that the knobs act chiefly as sense-fiber attachments. It is evident, judging merely from the structure of this organ, that gusts of wind and possibly weak air currents would cause the articular membrane to vibrate, thereby irritating the sense cells. This organ might also receive jar

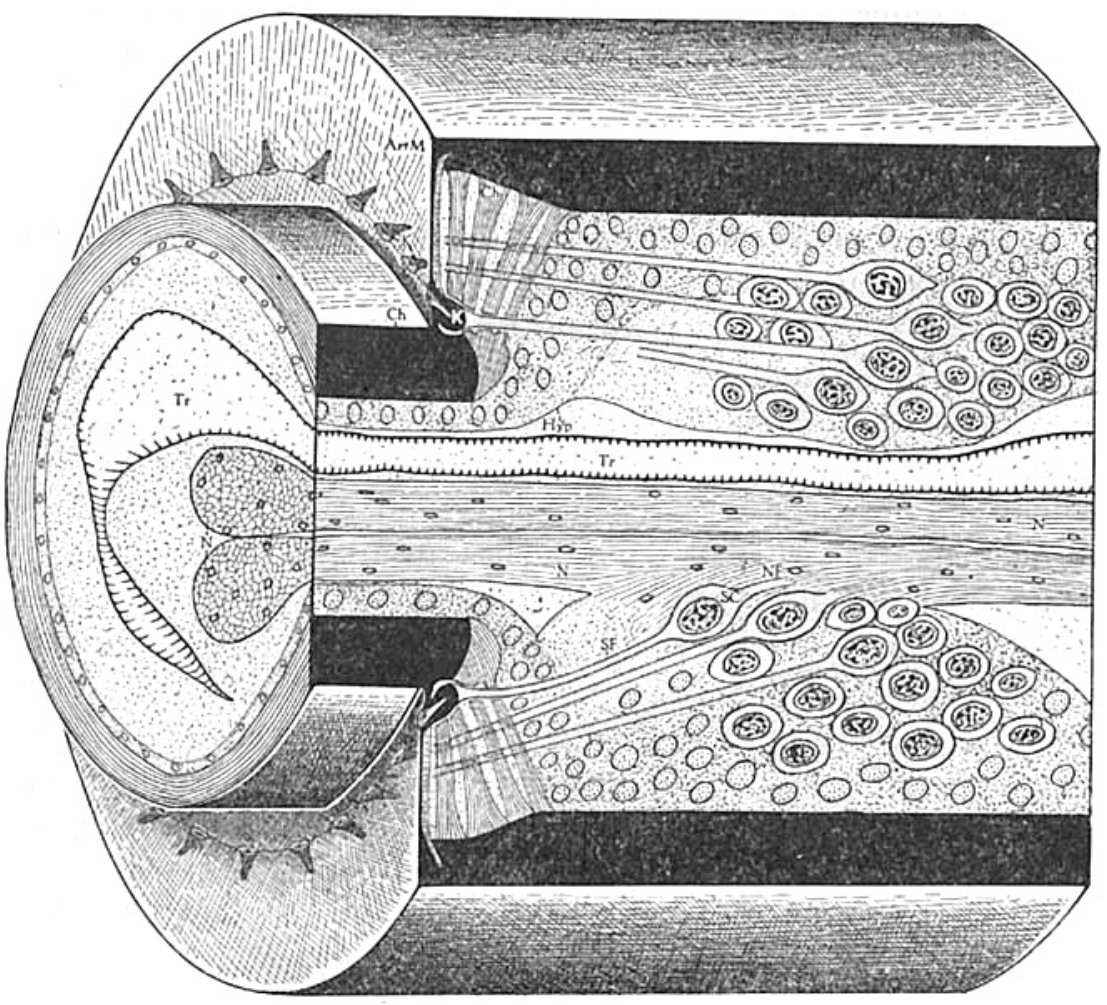

Fig. 12 Diagram, representing most of second antennal segment of worker honey-bee in longitudinal section and in perspective and a small portion of third segment in both cross and longitudinal section and in perspeetive, showing Johnston's organ which consists of two large groups of sense cells $(S C)$ whose nerve fibers $(N F)$ run into the two antennal nerves $(N)$ and whose sense fibers $(S F)$ are attached to the knobs $(K)$ in the articular membrane $(A r t M)$. Two of the knobs are cut lengthwise, showing the cone-shaped cavity which opens to the exterior, while the other knobs are heavily shaded, indicating that they are buried in the articular membrane. Tr, trachea; Hyp, hypodermis; $C h$, hard chitin; and $C h_{1}$, soft, flexible strands of chitin which firmly bind second and third segments together. 
stimuli, but it appears too crude to act as a sound-wave receptor, unless it is able to receive sound vibrations of a very low frequency. The most reasonable function that the writer can think of is the one suggested by Demoll ('17), that it may serve as a statical organ to register the movements of the flagellum. Since there can be no muscular sense in the flagellum, because this part of the antenna possesses no muscles, such an organ would seem very useful. The scape or first antennal segment (fig. 3, 1) contains many muscle fibers, most of which run to the articulation between the first and second segments. These muscles can only move the flagellum about in all directions, but cannot bend it. Since the antenna is the chief tactile organ of the bee and must be carefully operated, the only way of bending the manyjointed flagellum is by blood pressure. The blood bathes all the internal structures, and consequently any change in its pressure would affect the articular membrane. Even if the Johnston's organ in the honey-bee receives sound vibrations of a low frequency, or functions in any other way suggested above, we should probably classify it as a tactile organ rather than as an auditory organ.

Child ('94 b) says that the function of Johnston's organ is in general to receive original touch stimuli; it can, however, in a broader sense receive the stimuli of sound vibrations. The auditory stimuli are to be thought of as modified touch stimuli. When the same organ serves both as touch and auditory receptors, as is possible in mosquitoes and midges, then the insect will be able to differentiate between the touch response and auditory response.

According to Child, this organ is of hypodermal origin, arising from a ringlike fold near the antennal funnels which are invaginated in the head.

Several years ago the writer discovered two groups of olfactory pores on the base of the antenna, but they are here described for the first time. One group of about twenty-five pores lies among a bunch of tactile hairs on the distal end of the articular knob or condyle (fig. 3, Co), and the other group (Por) of twelve pores lies on the proximal end of the scape. So far as known, these are 
the only olfactory pores on the antenna of the honey-bee. The external and internal structure (fig. 8) are like those already described by the writer ('14 a).

b. Structure of pore plates. The pore plates or sensilla placodea, according to the writer's discussion of the antennal organs ('14 b), were first studied in 1847 by Erichson, who called them olfactory organs. Since this date they have been studied by about three dozen other investigators whose views concerning their function differ widely. In 1851 Vogt suggested that they perform a function combining those of smell and touch. In 1858 Lespés compared them to the ears of higher animals, and a year later Hicks called them auditory organs. Practically all of the other authors up to 1888 , who have studied the pore plates, regard them as olfactory organs. Ruland ('88), after having boiled antennae in caustic potash, saw that a pore plate is suspended on a membrane, resembling a double hinge, similar to that observed in sections stained in eosin by the present writer. Owing to this arrangement, he called them auditory organs. In 1894 Nagel favored the olfactory view, but also thought that the pore plates might have a mechanical function. He suggested that air pressure might affect them. Nine years later Schenk ('03) stated that the thick plates in these organs eliminated the possibility of these structures being olfactory organs, but judging from their anatomy he regarded them as having a mechanical function. He favors the view that they are pressure points to inform the bee of the object immediately in front of it.

According to Schenk's calculations, a male honey-bee has 31,356 pore plates and a female has only 3,648. According to the calculations of the present writer, a drone on an average has 29,718 pore plates; a worker has 4,744, and a queen has 2,776 . Those of the drone are much smaller than those of the worker or queen, but supposing that their sensitiveness is in direct proportion to the total area of all their plates, then if the sensitiveness of those on a worker equals 1, that of those on a drone equals 3 , and that of those on a queen equals only 0.6 . These organs (fig. 3, $P$ ) are found only on the fifth to twelfth antennal segments of the worker and queen, and on the fifth to thirteenth segments 
of the drone. They are rather equally distributed over the various segments. Using the average number of pore plates on a worker antenna as an example, the segments and number of these organs are: 5th, $322 ; 6$ th, $345 ; 7$ th, $332 ; 8$ th, $288 ; 9$ th, $284 ; 10$ th, $283 ; 11$ th, 278 , and 12 th, 240 . Twelve per cent of these lie on the ventral surface and 88 per cent on the dorsal surface. Relative to the pore plates on the queen and drone, only 3 per cent of those of the former and 25 per cent of the latter lie on the ventral surface of the antenna.

Viewed superficially with transmitted light, a pore plate (fig. $13, P)$ is seen to consist of an elliptical light spot, which is surrounded by three concentric bands; the first and third ones ( $a$ and $c$ ) being light in color, and the second or middle one $(b)$ being dark. A section through this organ shows that the hard and thick plate (figs. 9 and $13, P$ ) is suspended on a membrane $(m)$, resembling a double hinge, which viewed by transmitted light causes the above dark band $(b)$, while an inner groove $(d)$ causes the first light band $(a)$ and an outer groove $(e)$ produces the other light band (c). In reality this outer groove is not a true groove, because its walls or sides lie against each other and allow no cavity, except perhaps when the plate is vibrated. This fact explains why other observers have-overlooked it. Ruland saw it in sections made from caustic potash material, which must have been considerably distorted. The present writer has also seen it many times in the same kind of sections, besides in other sections made from material not treated with $\mathrm{KOH}$. Any dark stain obliterates this groove, and consequently the writer was able to see it by using eosin alone.

Judging from the structure of a pore plate, the elliptical plate (fig. 13, $P$ ) may be moved in and out on the double hinge $(m)$, thereby moving the large nerve strand $(S t)$ and consequently affecting the large sense cell group $(S C G)$. These organs, therefore, might be an air-pressure apparatus, as suggested by Nagel and Schenk. It has been observed by Schenk and the present writer that bees, when flying toward an object, such as a window, light on their feet instead of butting their heads into the object. Now, it may be that the pore plates act as an arr-pressure appara- 
tus, in which capacity they inform the insects of the objects immediately in front of them. In case of the honey-bee, they might also be sensitive to the weak currents of air caused by workers fanning. It is possible that the sense hairs are not affected by these weak currents, and therefore some method is

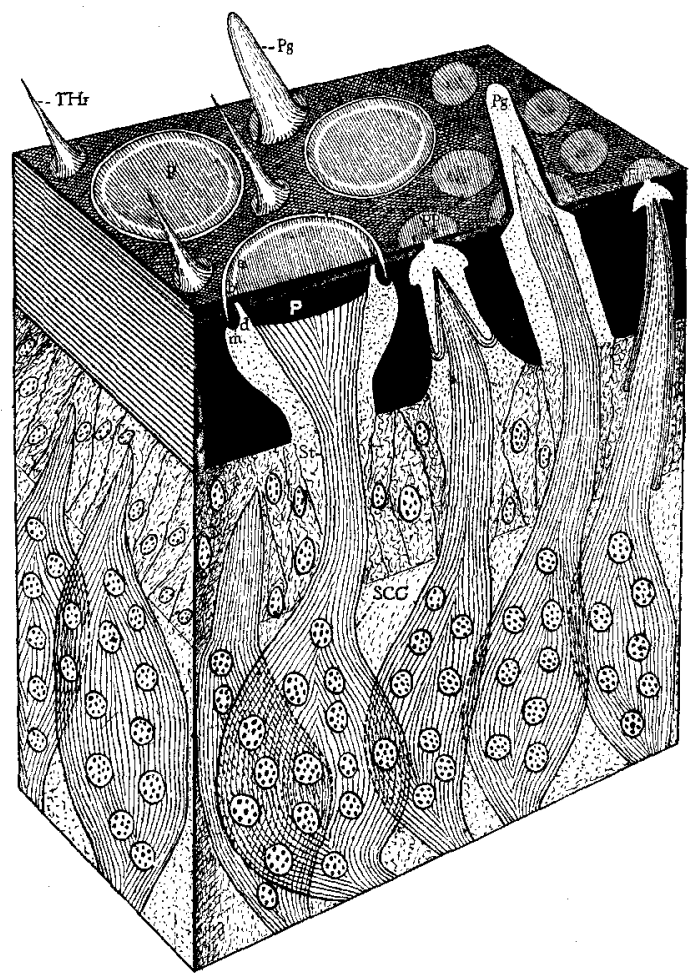

Fig. 13 Diagram, representing a block taken from terminal antennal segment of worker honey-bee, showing tactile hairs $(T h r)$, pegs $(P g)$, pit pegs $(P P)$, Forel flasks $(F l)$, and pore plates $(P)$ in both perspective and in section. $a$ and $c$, light colored bands; $b$, dark band; $d$, inner groove; and $m$, double, hinge-like membrane of pore plate; $S t$, nerve strand; $S C G$, sense cell group.

badly needed to keep the bees constantly informed whether or not the fanners are working properly. If these interpretations are correct, we here have another form of touch. Of course these organs might also be sensitive to wave vibrations of a very low frequency, but if this interpretation is correct, we would yet 
probably be more correct by classifying them as tactile organs rather than as auditory perceptors.

c. Structure of other antennal organs. Relative to the other antennal organs, there are four, all of which are really hairs. The tactile hairs (fig. 13, $T H r$ ) or sensilla trichodea are scarce on the antennae of the male honey-bees, but numerous on the antennae of the females. They are regarded by all the observers as tactile organs. The pegs $(P g)$ or sensilla basiconica are absent in the males, but numerous on the antennae of the females. They are generally considered as olfactory organs, because their tips are covered with very thin chitin. The present writer believes that they are very delicate touch organs.

The pit pegs (fig. 13, PP) or sensilla coeloconica and Forel flasks $(F l)$ or sensilla ampullacea are hairs inside of pits. On the antennae of the males both of these types are somewhat numerous, but on the antennae of the females they are comparatively scarce. Viewed superficially, one type cannot be distinguished from the other, but sections show that the pit pegs are usually the larger in diameter. Relative to the antennae of workers, most of these organs (fig. 3, $P P$ and $F l$ ) lie in groups on the sixth to twelfth segments, and counting both types combined there are not more than 100 individual organs on each antenna. In regard to their internal structure, they differ somewhat, as may be seen by referring to figures 10,11 , and 13 . In both types the semitransparent hair $(\mathrm{Hr})$ ends in a cavity $(\mathrm{Ca})$, which communicates with the exterior by a minute aperture $(A p)$, and each hair is connected with a nerve strand $(S t)$, which runs to a sense cell group $(S C G)$. The function of these organs is usually regarded as problematical, but still a few authors have called them auditory organs. The present writer has no conception of what their function is, but for some time he has looked upon them as more or less degenerated structures.

At this place the writer wishes to call attention to an erroneous idea which text-book writers still persist in handing down. Before understanding the internal anatomy of antennae, some of the early microscopists imagined that they saw gland cells among the masses of sense-cell groups. This led to the idea that in order 
for the antennal organs to function as olfactory or gustatory organs the secretion from these glands must pass through the thin chitin and must keep the outer surfaces of the organs moist and thus fitted for the reception of chemical stimuli. This is nice in theory, but there is not one iota of truth in such an assumption, because not one of the later investigators mentions having seen glands connected in any way with the antennal organs. Ruland in 1888 denies the presence of them, and the present writer has never seen anything in the antennae which he could call glands. Berlese ('09, p. 610) maintains that the essential feature of these chemical sense organs is the presence of antennal glands, and Comstock ('20, p. 133) quotes Berlese on this subject and then describes various types of hairs which have been called organs of smell and taste. The present writer ('16) does not believe that insects have a true gustatory sense and regards it absurd to consider any form of hair capable of receiving chemical stimuli.

d. Structure of tibial chordotonal organs. Schön ('11) described and illustrated the structure and development of the tibial chordotonal organs in the honey-bee and ants. The present writer has carefully studied the structure of the same organs in the honey-bee and differs with Schön only in a few details.

Sections through the tibiae of all three pairs of legs of workers and drones were made and a chordotonal organ was invariably found in each tibia sectioned. It lies (fig. 14, O) in the proximal end of the tibia, about one-fourth the distance from the femorotibial articulation to the tarsotibial articulation. This portion of the tibia is divided into two distinct chambers by the large trachea (figs. 15 and 16, Tr). The blood chamber (fig. 15, B) contains only blood and the chordotonal organ $(O)$, while the other chamber contains blood, muscles $(M)$, apodemes $(A)$, nerves $(N)$, fat-cells $(F)$, etc. In longitudinal sections this organ expands fan-like across the blood chamber and usually appears to be attached by its proximal end to the hypodermis (figs. 14 and $19, H y p$ ), but in other sections where the tibia is considerably compressed both its proximal and distal ends are attached to the hypodermis on the anterior side of the leg (fig. 19). In a series 
of cross-sections it may be seen to arise merely as a nerve attached to the hypodermis; then the nerve suddenly runs to a few large cells (fig. 15); a few sections further on the nerve disappears, and the organ assumes a spherical shape (fig. 16, $O$ ), and the walls are lined with a thick layer of large cells, leaving a cavity in the center, which is apparently filled with a liquid (probably only blood).

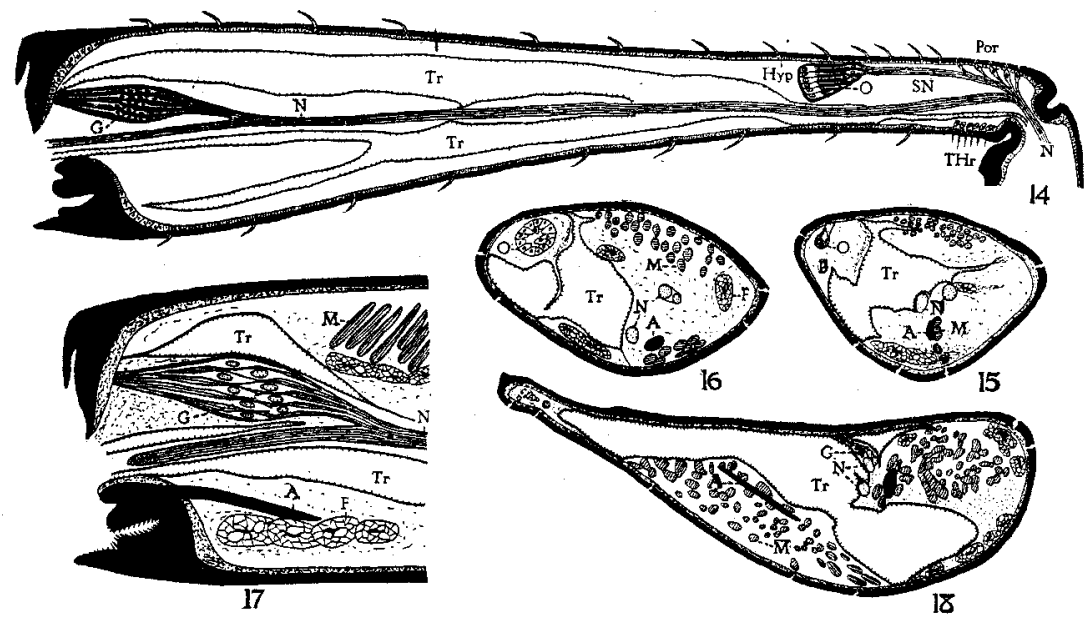

Figs. 14 to 18 Sections, showing structure of tibial sense organs. Figs. 14 and 17 , each a semidiagrammatic drawing from two consecutive longitudinal sections of hind tibia of a drone, showing relative position of tactile hairs $(\mathrm{THr})$, olfactory pores (Por), chordotonal organ $(O)$, and ganglion cells $(G)$, all of which are innervated by the same nerve ( $N$, too wide here), although a small branch of this nerve, called the subgenual nerve $(S N)$ runs directly to the chordotonal organ; fig. $14, \times 32$, and fig. $17, \times 53$. Figs. 15,16 , and 18 , cross-sections through tibia of a worker, showing relative position and shape of chordotonal organ $(O)$ and ganglion cells $(G) ; \times 53$; fig. 15, through proximal end of group of ganglion cells. $A$, apodeme; $B$, blood chamber; $F$, fat cell; $H y p$, hypodermis; $M$, muscle; $N$, two main branches of nerve; $T r$, trachea.

Using Schön's terminology, the detailed description of a single chordotonal organ is as follows. The tibial nerve after immediately emerging from the femur is apparently divided into two large branches, because in all of the cross-sections made two comparatively large nerves (figs. 15, 16, and 18, $N$ ) were found. A short distance from the femorotibial articulation one 
of the branches gives off fibers to some tactile hairs (fig. 14, $\mathrm{THr}$ ) and also a smaller branch which innervates the olfactory pores $(P o r)$ and the chordotonal organ $(O)$. Schön calls this small branch (figs. 14 and 19, $S N$ ) the subgenual nerve (Subgenualnerv). It runs into the sense cell group and gives off a fiber to each individual sense cell (fig. 19, SC). The spindle- but sometimes diamond-shaped sense cells lie in a mass which extends diagonally half-way across the blood chamber. In all of the present writer's sections, the organ is anchored at the base of the sense cell group, but only occasionally was it also fastened at the other end of the organ. According to Schön, it arises from the distal end and should always be fastened at this end. The distal end of a sense cell is terminated into a long, slender, sac-like enveloping cell $\left(E C\right.$, Umhüllungszelle) whose elongated nucleus $\left(N u c_{2}\right)$ sometimes nearly fills the entire lumen of the cell. Running the full length of the enveloping cell there is a dark-staining thread, the axial tube $(A x)$, which ends in a much darker staining body, the cone (Con, Stift), lying in the proximal end of the large oblong or pear-shaped cap cell (CC, Kappenzelle) whose nucleus $\left(N u c_{3}\right)$ usually lies in the distal end.

The walls of the axial tube correspond to the extended walls of Schön's Stift. Schön also describes two other types of cells which the present writer has not been able to differentiate from those just mentioned. His accessory cells (akzessorische Zellen) lie between the cap cells and his end fibers (Endfasern), which fasten the organ to the hypodermis.

A more careful study of the sensory element of the chordotonal organ under a magnification of $\mathbf{1 9 0 0}$ diameters shows the following: Lying around the conspicuous nucleus (figs. 19 and 20, $N u c)$ of the sense cells $(S C)$ there are large dark-staining particles, the largest one of which seems to be the tail end of the axial tube $(A x)$. In longitudinal sections this particle appears as a dark streak and may or may not reach as far as the nucleus. In cross-sections it appears as a large, dark, solid particle (fig. 21). Cross-sections through the proximal end (fig. 22), middle portion (fig. 23), and distal end (fig. 24) of the enveloping cell $(E C)$ show that instead of the axial tube continuing very far as a rod, 


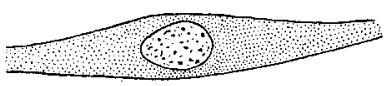

25

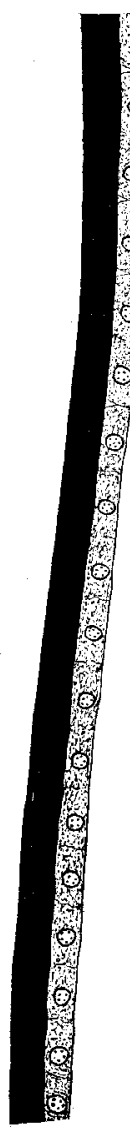

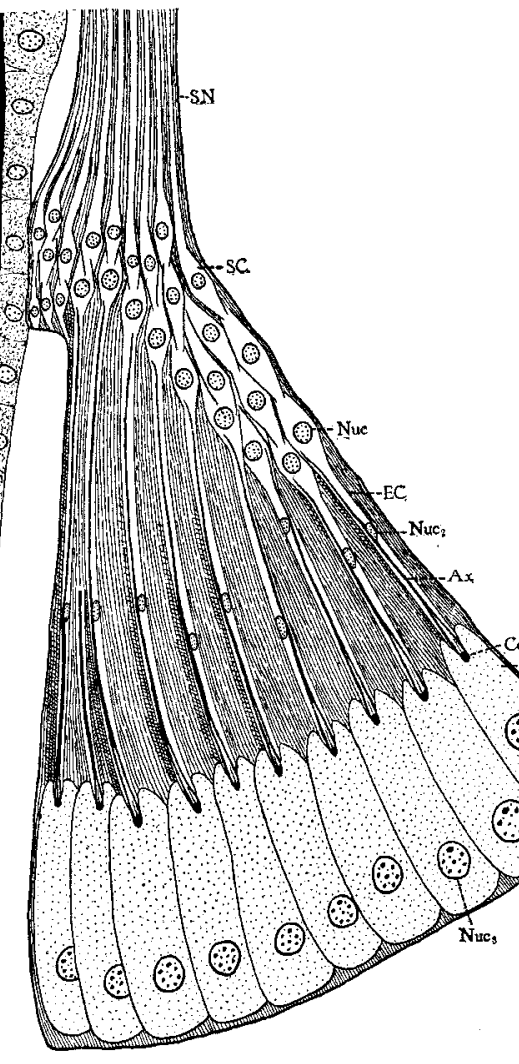

19
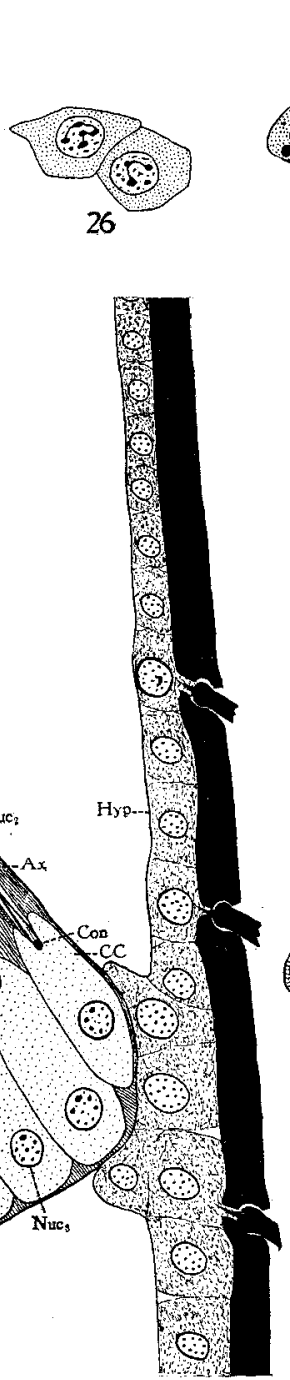
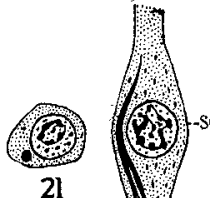

2l

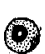

22

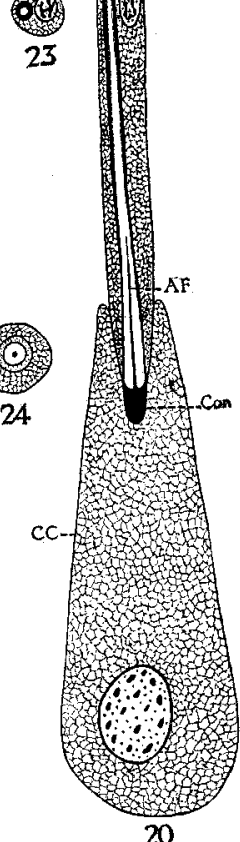

Figs. 19 to 26 Sections, showing detailed structure of chordotonal organ and ganglion cells. Fig. 19, semidiagrammatic drawing from several longitudinal sections through anterior portion at proximal end of hind tibia of a drone, twentyone days old, showing chordotonal organ suspended in blood chamber, but attached at both ends to hypodermis $(H y p) ; \times 320$. Fig. 20, longitudinal view of one of the sensory elements from fig. 19, showing following parts in detail; sense cell $(S C)$, axial tube $(A x)$, enveloping cell $(E C)$, axial fiber $(A F)$, cone $(C o n)$, cap cell $(C C)$, and nuclei $\left(N u c_{1}, N u c_{2}\right.$ and $\left.N u c_{3}\right)$ of sense cell, enveloping cell and cap cell, respectively. Fig. 21, cross-section of sense cell (SC) through nucleus, showing tail end (large dot) of axial tube; figs. 22,23 , and 24, crosssections of proximal end, of middle portion through nucleus, and of distal end, respectively, of enveloping cell, showing appearance of axial tube $(A x)$ and its fiber $(A F)$. Fig. 25, longitudinal section, and fig. 26, cross-section of ganglion cells from tibia of a drone. Figs. 20 to $26, \times 1000$. 
it becomes a tube with thick walls at first, but the walls gradually become thinner and thinner as one glances at them from the proximal end to the distal end. The outer layer of the walls seems solid, often does not take the stain, but remains a light yellow color. The inner layer does not appear totally solid, but usually is stained more or less. The axial tube seems harder than the surrounding tissue and occasionally the microtome knife fails to cut it, thus leaving it slightly projecting from a cross-section. Hence from all appearances the axial tube is a semichitinous structure.

The head end of the axial tube terminates in the cone (fig. 20, $C o n)$, from the center of which arises the short axial fiber $(A F)$, scarcely visible under the highest magnification. In position this fiber corresponds to the Schön's axial fiber, which extends the full length of the enveloping cell. Figure 24 shows the relation of the various parts in cross-section just in front of the cone. The dot represents the axial fiber; the inner circle, the walls of the axial tube; the middle circle, the walls of the enveloping cell, and the outer circle, the walls of the cap cell.

The cytoplasm in the distal half of the enveloping cell and in the cap cell (fig. 20,CC) appears slightly net-like, although this appearance is exaggerated in figures 20,23 , and 24 .

In regard to the development of the chordotonal organ, Schön says that eight days after the honey-bee egg is laid a small growth projecting into the blood chamber is seen developing in the hypodermal cells in the tibia from which the organ arises. On the ninth day may be seen the first differentiation of cells, and on the tenth and eleventh days one may distinctly see sense cells, enveloping cells, and cap cells. On the eleventh and twelfth days the cone is formed, and on the thirteenth day the nervous part of the organ is laid down in the blood chamber. On the fifteenth and sixteenth days the end fibers are developed, and on the seventeenth day the organ is fully developed. It is of a purely ectodermal formation.

Schön says that since the trachea is so greatly expanded where the chordotonal organ occurs, it may probably have something to do with the function of this organ; but the present writer does 
not think so, because the trachea does not come in contact with the organ and is no more expanded here than in other places in the tibia.

So far no external device or apparatus connecting with the internal organ has been found, although Schön imagined that he had found the external portion when he thought he saw two rows of sense cones (Sinneskegel) on the proximal end of each tibia. In position and number these cones correspond exactly to the olfactory pores described by the present writer. When observed without the cylindrical tibia being properly rotated, they often externally resemble cones; but when the tibia is rotated slightly, so that they lie on the median line of the tibia, the optical illusion becomes evident. Schön found that both the chordotonal organ and these imaginary cones are innervated by the subgenual nerve, and consequently he believes that the cones act as the external apparatus of the organ. Schön describes and illustrates the internal anatomy of his sense cones (the present writer's olfactory pores), but here does not recognize them as cones, for he follows vom Rath by calling them membrane canals (Membrankanäle).

Nothing can be said about the probable function of the chordotonal organ, but if it were connected with an external apparatus, similar to that found in some Orthoptera, it might serve as an auditory organ.

Schön says that there is a great similarity between this organ in Hymenoptera and that in Orthoptera. These organs in bumble-bees, wasps, and Terebrantidae vary greatly with those in ants and honey-bees. In all the organ is fastened to the hypodermis and in all he found the sense cones and spindle-shaped sense cells which with the subgenual nerve protrude into the nervous ends of the enveloping cells.

e. Structure of tibial ganglion cells. In the first longitudinal sections made, the writer observed a group of supposedly sense cells which he thought was associated with the chordotonal organ, but after studying more sections it was ascertained that these cells are totally independent of the chordotonal organ, because the former (fig. 14, $G$ ) are located at the distal end of the tibia 
and the latter $(O)$ at the proximal end of the tibia, and no connection could be found between them, except that the same nerve $(N)$ sends off a branch to each group of cells.

For lack of a more appropriate name, the cells under discussion may be called tibial ganglion cells, although the writer knows of no similar group in insects. Schön apparently did not see them and perhaps this is the first time for them to be described. They lie in a mass (fig. 17, $G$ ) between two tracheae $(T r$ ) at the extreme distal end of the tibia. The distal end of the group is attached to the hypodermis near the articulation, while the proximal end terminates in a branch of the main nerve.

Figure 18 is a cross-section showing this group of cells $(G)$ just departing from the nerve $(N)$, and some of the fibers may be seen between the two tracheae ( $T r$ r) running to the hypodermis.

This group of cells is slightly larger than the chordotonal organ, but the individual cells (figs. 25 and 26) in it are practically the same in shape and size as are the sense cells in the chordotonal organ.

\section{SUMMARY}

Bee-keepers are agreed that bees can hear, yet they cannot prove it, and critics still contend that it has never been experimentally proved that any insect can hear; nevertheless, within the last few years some good experimental results have been obtained.

The special sound-producing apparatus of the honey-bee consists of the membranes lying between the axillaries at the bases of the front wings. Muscles, lying in the thorax and attached to these axillaries, contract and relax very quickly, thereby causing the axillaries to vibrate; consequently, the above membranes are caused to vibrate rapidly, thus producing the piping, teeting, or squealing noise commonly heard when a bee is squeezed.

Up to date five so-called auditory organs have been found in the honey-bee. Judging from their anatomy, the pore plates, Forel flasks, pit pegs, and Johnston's organ, all located in the antennae, do not seem to be well fitted to act as sound receptors; but the chordotonal organs, lying in the tibiae might be better 
adapted for this purpose, providing they had an external portion, corresponding to the tympanum.

The Johnston's organ, lying in the second antennal segment, consists of the peculiarly modified articular membrane between the second and third antennal segments and of many sense cells whose fibers unite with peculiar knobs extending inwardly from the articular membrane. This organ does not seem well adapted to act as an auditory organ unless it is able to receive sound vibrations of a very low frequency. It might also be sensitive to weak air currents and possibly to jars, but the most reasonable function that the writer can think of is that it may serve as a statical organ to register the movements of the flagellum.

The pore plates, lying so abundantly on the antennae and called olfactory organs by most of the other authors, were found to have two grooves encircling each elliptical plate, thereby allowing the plate to move in and out on a double hinge. Judging from this mechanism, the pore plates might act as an air-pressure apparatus to inform the bees of an object immediately in front of them, and thus prevent them from striking against objects. They might also be sensitive to the weak air currents made by workers fanning, thereby serving as an apparatus to keep the bees constantly informed whether or not the fanners are working properly.

The functions of the Forel flasks and pit pegs are problematical.

The chordotonal organs, found in the proximal ends of the tibiae, are very complicated in structure and are similar to those found in the tibiae of crickets and katydids, but the former do not have external membranes, while the latter do. Nothing can be said about the function of the chordotonal organs in honey-bees.

A group of ganglion cells was found in the extreme distal end of each tibia, but nothing can be said about its function.

In conclusion, it may be that the sense of hearing in insects is on no higher plane than that advocated by Forel ('08), who believes that insects do not hear, at least as we do, but compares this perception in them to that in deaf-mutes who feel the rolling of a carriage at a distance. Forel says: 
Hearing is a physical sense. Sonorous waves, especially those of low sounds, are nearer to large mechanical vibrations than luminous, caloric, or electric waves. Hearing, therefore, must be in its origin connected with touch, but we make a distinct difference between the perception of a very low sound by touch and its perception by hearing. We must not forget that the specialization of the organ of hearing has reached in man a delicacy of detail which is evidently not found again in lower vertebrates. It is, I believe, the sense which removes us most from the lower animals. In animals as high as fish the auditory nerve is confused with other nerves, and the portion of the labyrinth most specially affected by our audition, the cochlea, has disappeared.

\section{LITERATURE CITED}

Adbin, P. A. 1914 The buzzing of Diptera. Jour. Royal Micr. Soc., pp. 329-334.

Berlese, Antonio 1909 Gli Insetti, vol. 1, Milano.

Child, C. M. 1894 a Beiträge zur Kenntnis der antennalen Sinnesorgane der Insecten. Zool. Anz., 17. Jahr., S. 35-38.

$1894 \mathrm{~b}$ Ein bisher wenig beachtetes antennales Sinnesorgan der Insekten, mit besonderer Berücksichtigung der Culiciden und Chironomiden. Zeitsch. f. wiss. Zool., Bd. 58, S. 475-528.

Comstock, J. H. 1920 An introduction to entomology. Part I, 2nd ed, Ithaca, N. Y.

Demold, Rernhard 1917 Die Sinnesorgane der Arthropoden, ihr Bau und ihre Funktion. Braunschweig.

Forde, Auguste 1908 The senses of insects. English trans. by Yearsley. London.

Janet, Charles 1911 Sur l'existence d'un organe chordotonal et d'une vésicule pulsatile antennaires chez l'abeille et sur la morphologie de la tête de cette espèce. L'Apiculteur, 55e Année, no. 5, May, pp. 181-183.

Johnston, Chr. 1855 Auditory apparatus of the Culex mosquito. Jour. Micr. Sci., Old Series, vol. 3, pp. 97-102.

McIndoo, N. E. 1914 a The olfactory sense of the honey-bee. Jour. Exp. Zool., vol. 16, no. 3, pp. 265-346.

$1914 \mathrm{~b}$ The olfactory sense of insects. Smithsn. Misc. Collect., vol. 63 , no. 9, pp. 1-63.

1916 The sense organs on the mouth-parts of the honey-bee. Smithsn. Misc. Collect., vol. 65, no. 14, pp. 1-55.

1920 The olfactory sense of Orthoptera. Jour. Comp. Neur., vol. 31, no. 5 , pp. $405-427$.

Pemberton, C. E. 1911 The sound-making of Diptera and Hymenoptera. Psyche, vol. 18, pp. 114-118.

Ruland, Franz 1888 Beiträge zur Kenntniss der antennalen Sinnesorgane der Insekten. Zeitsch. f. wiss. Zool., Bd. 46, S. 602-628.

Schenk, Oтто 1903 Die antennalen Hautsinnesorgane einiger Lepidopteren und Hymenopteren, mit besonderer Berücksicktigung der sexuellen Unterscheide. Zool. Jahrb., Bd. 17, S. 573-618. 
SснӧN, Arnold 1911 Bau und Entwicklung des tibialen Chordotonalorgane bei der Honigbiene und bei Ameisen. Zool. Jahrb. Anat. und Ont., Bd. 31, S. 439-472.

Snodgrass, R. E. 1910 The anatomy of the honey-bee. U. S. Dept. Agr., Bur. Ent. Tech. Ser. 18.

Torner, G. H., and Schwarz, E. 1914 The auditory powers of the Catocala moths; an experimental field study. Biol. Bul., vol. 27, no. 5, pp. 275-293.

TurNer, C. H. 1914 An experimental study of the auditory powers of the giant silkworm moths (Saturniidae). Ibid., no. 6, pp. 325-332.

Von Buttel-Rempen, H. 1907 Are bees reflex machines? pp. 1-48. English trans. by Mary H. Geisler, A. I. Root Co., Medina, Ohio. 